\title{
A INFLUÊNCIA LUNAR NA CAPTURA DE MORCEGOS (MAMMALIA, CHIROPTERA) NA SERRA DA JIBOIA, RECÔNCAVO SUL DA BAHIA
}

\author{
Bruna da Silva Sampaio ${ }^{1}$; Téo Veiga de Oliveira ${ }^{2}$. \\ 1. Bolsista PROBIC/UEFS, Graduando em Bacharelado em Ciências Biológicas, Universidade Estadual de Feira de \\ Santana, e-mail: sampaiobruna55@yahoo.com \\ 2. Orientador, Departamento de Biologia, Universidade Estadual de Feira de Santana, e-mail: teovoli@yahoo.com.br
}

PALAVRAS-CHAVE: Quirópteros; Mata Atlântica; Bahia.

\section{INTRODUÇÃO}

Morcegos são alguns dos principais componentes das mastofaunas neotropicais, representando uma parcela bastante significativa do total de mamíferos amostrados nos diferentes ambientes (Reis et al. 2007). No Brasil, das cerca de 700 espécies de mamíferos conhecidas em nosso país, cerca de 175 são morcegos (Nogueira et al. 2014). Morcegos costumam ser animais abundantes nos ambientes onde vivem, formando, em muitos casos, grandes colônias que desempenham um papel importante nos ecossistemas (Reis et al. 2013). Alguns mamíferos, incluindo morcegos, apresentam alterações comportamentais durante as diferentes fases da lua em resposta à luminosidade lunar. Esta alteração é chamada de "fobia lunar" e já foi observada em alguns trabalhos anteriores (e.g. Breviglieri, 2011; Mello et al. 2013). A importância destes animais, mencionada acima, apenas reforça a necessidade em investir mais tempo em reconhecer as faunas de quirópteros brasileiros, especialmente em biomas onde a riqueza de espécies ainda é, provavelmente, bastante subestimada, como no caso da Mata Atlântica. Os objetivos deste trabalho incluem a elaboração de uma lista das espécies de morcegos encontradas na Serra da Jiboia, o cálculo das abundâncias absoluta e relativa de cada espécie registrada e a análise de dados para verificar a ocorrência de influência lunar na captura de morcegos.

\section{MATERIAL E MÉTODOS}

O maciço serrano da Serra da Jiboia localiza-se na região do Recôncavo Sul da Bahia, com uma extensão de aproximadamente 44.000 hectares, onde encontra-se a mais significativa área de Mata Atlântica do Recôncavo Sul Baiano, com 32\% do remanescente florestal (7.200 ha) em estado avançado de regeneração e quase contínuo (Carvalho-Sobrinho et al. 2005). Grande parte dos trabalhos de campo já havia sido realizada, logo muitos dados já estavam disponíveis para que as análises de composição das faunas de morcegos da Serra da Jiboia fossem feitas. Os morcegos foram capturados com redes de neblina de malha de $20 \mathrm{~mm}$, com $3 \mathrm{~m}$ de altura e $12 \mathrm{~m}$ de comprimento, em locais escolhidos durante as expedições de campo, durante seis noites consecutivas (Reis et al., 2010). Cada indivíduo capturado passou por biometria, foi pesado e teve o sexo determinado. Os indivíduos foram identificados com o auxílio de guias de campo (e.g. Reis et al., 2013). O ciclo lunar foi analisado através da porcentagem da face iluminada (Breviglieri, 2011), obtida através do programa Moontool for Windows 2.0. A riqueza de espécies observada a cada noite de coleta e a taxa de captura foram analisadas através de uma relação linear, com o auxílio do programa Past versão 3.2. 
Para avaliar a relação entre a riqueza de espécies e a taxa de captura [calculada como 'número de indivíduos / (número de redes x horas de amostragem)'; Breviglieri, 2011] foram considerados apenas os dados das expedições de campo com o mesmo esforço de captura (Esbérard, 2007). Também foi produzida uma curva de rarefação no programa EstimateS 9.1.0 para avaliar a riqueza estimada para a área e a adequação do esforço amostral empreendido.

\section{RESULTADOS E DISCUSSÃO}

Seis áreas distribuídas ao longo da Serra foram amostradas: Baixa de Areia, Reserva Jequitibá, Baixa Grande, Pioneira, Fazenda Pancada e Fazenda Baixa de Areia. O esforço de captura foi de $22.769 \mathrm{~m}^{2}$ de rede-hora. Foram capturados 340 indivíduos de 28 espécies diferentes (Tabela 1). A análise da curva de rarefação produzida no software EstimateS apontou uma riqueza estimada de 30,88 $\pm 2,31$ espécies para a área e a curva ainda mostrava caráter ascendente, demonstrando que o esforço amostral deveria ser aumentado.

Tabela 1. Lista de espécies capturadas nas seis localidades de amostra (Abreviações: FBA, Fazenda Baixa de Areia; RJ, Reserva Jequitibá; FBG, Fazenda Baixa Grande; FPA, Fazenda Pancada; PIO, Pioneira; RG, RPPN Guarirú; nT, número total de indivíduos).

\begin{tabular}{|c|c|c|c|c|c|c|c|c|}
\hline Espécie & FBA & $\mathbf{R J}$ & FBG & PIO & FPA & RG & $\begin{array}{l}\text { Abundância } \\
\text { total (nT) }\end{array}$ & $\begin{array}{c}\text { Abundânci } \\
\text { a relativa } \\
(\%)\end{array}$ \\
\hline Peropteryx kappleri & 0 & 0 & 0 & 0 & 1 & 0 & 1 & 0,3 \\
\hline Rhinconycteris naso & 6 & 0 & 0 & 0 & 0 & 0 & 6 & 1,7 \\
\hline Saccopteryx leptura & 1 & 1 & 0 & 0 & 0 & 0 & 2 & 0,6 \\
\hline Desmodus rotundus & 18 & 0 & 2 & 0 & 5 & 6 & 31 & 9 \\
\hline Diphylla ecaudata & 1 & 0 & 0 & 0 & 0 & 0 & 1 & 0,3 \\
\hline Anoura caudifer & 0 & 0 & 0 & 1 & 0 & 0 & 1 & 0,3 \\
\hline Anoura geoffroyi & 0 & 0 & 1 & 0 & 0 & 1 & 2 & 0,6 \\
\hline Glossophaga soricina & 0 & 0 & 3 & 0 & 1 & 5 & 9 & 2,6 \\
\hline Carollia brevicauda & 8 & 0 & 2 & 2 & 4 & 0 & 16 & 4,6 \\
\hline Carollia perspicillata & 72 & 1 & 12 & 25 & 18 & 38 & 166 & 48 \\
\hline Rhinophylla pumilio & 2 & 0 & 0 & 1 & 1 & 0 & 4 & 1,2 \\
\hline Lophostoma brasilienses & 1 & 0 & 0 & 0 & 0 & 0 & 1 & 0,3 \\
\hline Phyllostomus hastatus & 1 & 0 & 0 & 0 & 0 & 0 & 1 & 0,3 \\
\hline Tonatia bidens & 1 & 0 & 0 & 0 & 0 & 0 & 1 & 0,3 \\
\hline Tonatia saurophilla & 2 & 1 & 0 & 0 & 0 & 0 & 3 & 0,9 \\
\hline Trachops cirrhosus & 0 & 0 & 0 & 0 & 1 & 0 & 1 & 0,3 \\
\hline Micronycteris hirsuta & 0 & 4 & 0 & 0 & 0 & 0 & 4 & 1,2 \\
\hline Micronycteris minuta & 0 & 0 & 0 & 0 & 3 & 0 & 3 & 0,9 \\
\hline Artibeus fimbriatus & 5 & 0 & 1 & 3 & 0 & 2 & 11 & 3,2 \\
\hline Artibeus lituratus & 7 & 0 & 1 & 0 & 0 & 2 & 10 & 2,9 \\
\hline Artibeus planirostris & 11 & 1 & 6 & 0 & 0 & 1 & 19 & 5,5 \\
\hline Dermanura cinerea & 3 & 0 & 1 & 0 & 0 & 3 & 7 & 2 \\
\hline Platyrrhinus lineatus & 1 & 4 & 4 & 0 & 0 & 4 & 13 & 3,8 \\
\hline Sturnira lilium & 1 & 0 & 0 & 0 & 1 & 0 & 2 & 0,6 \\
\hline Sturnira tildae & 2 & 0 & 0 & 2 & 0 & 5 & 9 & 2,6 \\
\hline Myotis lavali & 12 & 1 & 0 & 0 & 1 & 0 & 14 & 4 \\
\hline
\end{tabular}




\begin{tabular}{lllllllll}
\hline Platyrrhinus recifinus & 1 & 0 & 0 & 0 & 0 & 0 & 1 & 0,3 \\
\hline Lasiurus blossevillii & 1 & 0 & 0 & 0 & 0 & 0 & 1 & 0,3 \\
\hline
\end{tabular}

A espécie mais abundante foi Carollia perspicillata $(n=166)$, representando cerca de $48 \%$ do total de capturas (Tabela 1); a dominância da espécie fica ainda mais evidente quando comparada à segunda espécie mais abundante, Desmodus rotundus $(\mathrm{n}=31)$, com apenas $9 \%$ de abundância relativa. Carollia perspicillata foi a única espécie registrada nas seis áreas amostradas. A Fazenda Baixa de Areia foi a área com o maior número de indivíduos capturados $(n=156)$ e aquela onde a maior riqueza foi observada com 20 espécies registradas. O maior número de espécies foi obtido com $76-100 \%$ da face iluminada e o menor número de espécies com 0 a $25 \%$ da face iluminada da lua ( $\mathrm{p}=$ 0,093609) (Fig. 1). A maior taxa de capturas foi observada na fase de $76-100 \%$ da face iluminada e a menor em $0-25 \%(\mathrm{p}=0,8708)$ (Fig. 2).

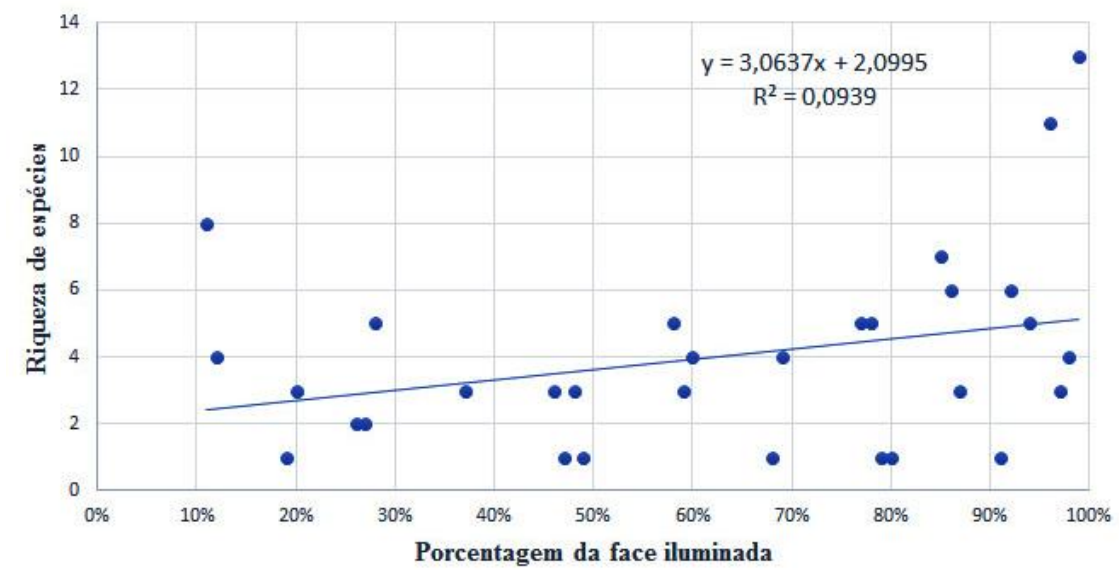

Fig. 1. Variação da riqueza de espécies (em 31 noites de capturas) em relação à porção iluminada da lua.

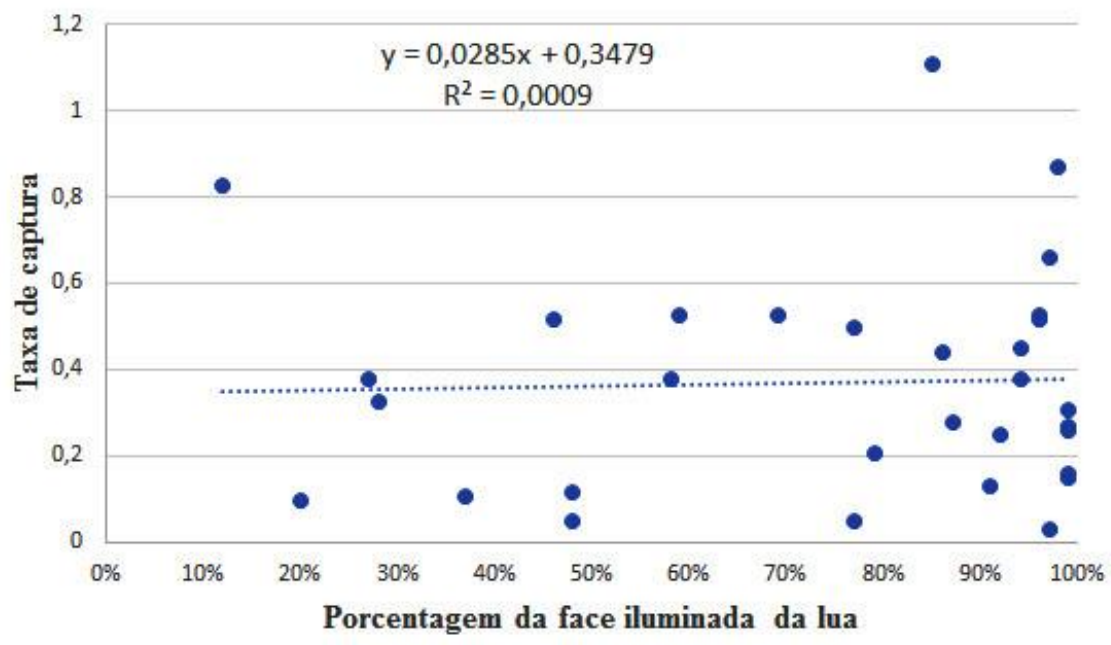

Fig. 2. Variação da taxa de captura de morcegos (em 31 noites de capturas) em relação à porção iluminada da lua.

Quanto à possível fobia lunar dos morcegos, aparentemente a hipótese de que estes animais diminuíssem suas atividades em momentos onde grande parte da superfície lunar estivesse iluminada não é válida, já que a taxa de captura de indivíduos parece não ser influenciada de forma significativa pela porcentagem de face lunar iluminada ( $\mathrm{p}=$ 
0,8708), resultado parecido foi obtido em outros trabalhos, porém estes mensuravam também o nível de sombreamento efetivo pela cobertura vegetal e altura na qual os indivíduos foram capturados (e.g. Esbérard, 2007). A riqueza de espécies também foi mais alta quando a porcentagem da porção iluminada da lua era maior, um resultado esperado se considerarmos os dados de outros trabalhos (e.g. Esbérard, 2007), embora não haja relação significativa entre estas duas variáveis $(\mathrm{p}=0,093609)$, indicando que a fobia lunar pode ser descartada no caso analisado.

\section{CONCLUSÃO}

A riqueza de 28 espécies, observada na Serra da Jiboia, está em um nível intermediário a outros inventários realizados em áreas de Mata Atlântica no estado da Bahia, os quais apontaram de 13 a até 59 espécies (e.g. Morais \& Freitas, 1999) sendo evidente a necessidade de um esforço amostral maior para obter a real riqueza de morcegos da região, conforme sugerido pela curva de rarefação de espécies. A riqueza de morcegos na Serra da Jiboia é bastante significante, especialmente levando-se em conta os poucos trabalhos realizados na área a respeito das faunas de morcegos desta importante porção do Corredor Central da Mata Atlântica. Isto apenas reforça a necessidade em ampliar os estudos e a conservação desta área. Embora este estudo seja preliminar, no que diz respeito a possíveis efeitos da luminosidade lunar na captura de morcegos, é importante ressaltar que outros parâmetros como a influência do dossel, a nebulosidade e o local onde as redes são colocadas devem ser considerados em estudos futuros para uma melhor análise e compreensão dos dados.

\section{REFERÊNCIAS}

Breviglieri, C.P.B. 2011. Influência do dossel na atividade de morcegos (Chiroptera: Phyllostomidae) em três fragmentos no estado de São Paulo. Chiroptera Neotropical 17(1). Carvalho-Sobrinho, J. G. \& Queiroz, L.P. 2005. Composição florística de um fragmento de Mata Atlântica na Serra da Jibóia, Santa Teresinha, Bahia. Sitientibus.

Esberard, C.E.L. 2007. Influence of moon cycle in phyllostomid bat capture. Iheringia, Série Zoologia, 97 (1): 81-85.

Mello, M. A. R; Kalko, E.K.V \& Silva, W.R. 2013. Effects of moonlight on the capturability of frugivorous phyllostomidbats (Chiroptera: Phyllostomidae) at different time scales. Zoologia 30 (4): 397-402.

Morais, E.P.F. \& Freitas, M.A. 1999. Levantamento da ornitofauna e mastofauna da Serra da Jibóia, municípios de Santa Terezinha e Elísio Medrado, Bahia; p. 453, in: 12th Encontro de Zoologia do Nordeste [unpublished report]. Feira de Santana, ON.

Nogueira, M.R.; Lima, I.P.; Moratelli, R.; Tavares, V.C.; Gregorin, R. \& Peracchi, A.L.. 2014. Checklist of Brazilian bats, with comments on original records. CheckList 10(4): 808-821.

Reis, N.R.; Peracchi, A.L.; Pedro, W.A. \& Lima, I.P. 2007. Morcegos do Brasil. Londrina, 253p.

Reis, N.R.; Peracchi, A. L.; Rossaneis, B.K. \& Fregonezi, M.N. 2010. Técnicas de estudo aplicadas aos mamíferos silvestres brasileiros. Rio de Janeiro: Technical Books, 275p.

Reis, N.R.; Fregonezi, M.N.; Peracchi, A. L. \& Shibatta, O.A. 2013. Morcegos do Brasil: guia de campo. Rio de Janeiro: Technical Books, 252p. 